\title{
The Process of Personalized Learning Based on Flipped Classroom
}

\author{
ZHANG Fan \\ Central South University of Forestry \& Technology, Hunan, China \\ FENG Shu-xiong \\ Hunan Normal University, Hunan, China
}

\begin{abstract}
The new teaching mode of flipped classroom plays an important role in college English teaching reform in China. Personalized learning can be realized by flipped classroom. Firstly, selection and production of the teaching content before class is very important. Secondly, the organization of teaching activities in class should be well prepared. At last, the realization of combining personalized evaluation and integrity evaluation system is a vital issue for teachers to consider.
\end{abstract}

Keywords: personalized learning, flipped classroom, micro-video, evaluation system

\section{Introduction}

In China, in addition to the use of the popular abroad teaching video as the media of teaching content, according to China's current national conditions, the guiding paper plans are used to realize the transmission of teaching content by some schools. Therefore, videos in the teaching mode of flipped classroom are important, but not necessarily the essential basic elements.

When carrying out the teaching design, we should fully consider the degree of fitness between teaching purposes and videos, that is to say, we should think carefully about whether the teaching videos are the most suitable teaching content transmission means in comparison with other ways. If there is no absolute advantage over others, we should not use teaching videos just for "using videos". However, once the decision to adopt teaching videos as the media of teaching contents is made, teachers will face many problems: One is that the most English teachers might be fearful of modern technology and software and the second is that the teaching content of college English is often not as much logic as that of science courses. As a result, once it is confirmed that the video is the best means of acquiring knowledge for students, teachers who turn to participate in flipped classroom teaching will face huge challenges technically and mentally. In addition to the technical difficulties, the content and the structure of college English curriculum also make the teaching video production more difficult. In the practice of teaching, teachers can adopt the existing teaching videos or make videos by themselves. Careful selection and effective use of video resources available can greatly save the time and energy of teachers who practice flip classroom teaching mode. In addition, some other network resources, such

\footnotetext{
ZHANG Fan, lecturer, M.A., College of Foreign Languages, Central South University of Forestry \& Technology, Hunan, China.

FENG Shu-xiong, assistant, M.A., Office of International Exchange and Cooperation, Hunan Normal University, Hunan,
} China. 
as the World Famous Universities Public Classes, China National High-quality Courses, Micro Class Network and so on, provide the teachers abundant and high-quality resources of teaching videos. This method has saved teachers a lot of time, and on the other hand, it can relieve the great pressure of facing the camera for a large number of teachers. The sharing of network resources becomes an important leverage for education resources. At the same time, another advantage of borrowing teaching videos is to let students realize that they can get the information they need through other channels, making them realize that learning is their own thing and collecting information is very important for learning.

But the teaching mode of flipped classroom is relatively new, therefore, resources of teaching videos which are suitable for college English teaching are scarce. The difference between existing films and televisions and teaching video resources is bigger. First of all, the main purpose of the audience' appreciating the existing video resources is for entertainment. Meanwhile the content is not so logic, the structure is relatively loose, and the details occupy most of the time.

\section{Preparation at Pre-class Stage}

Firstly, the selection and production of the teaching content before class should be well prepared.

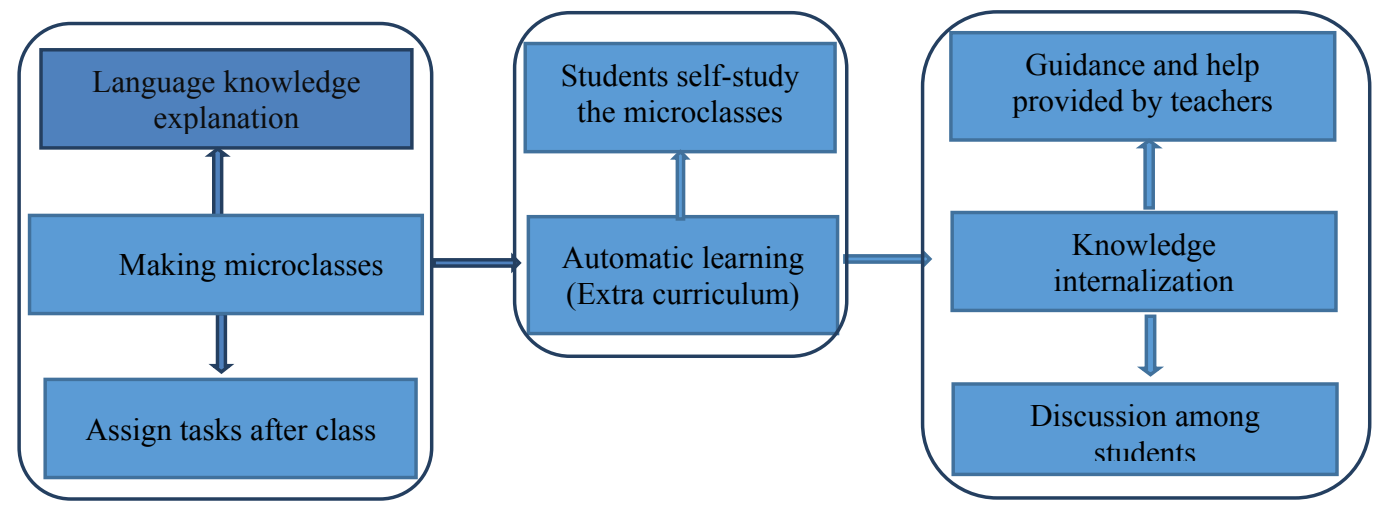

Figure 1. The process of flipped classroom.

The basic procedure is as follows:

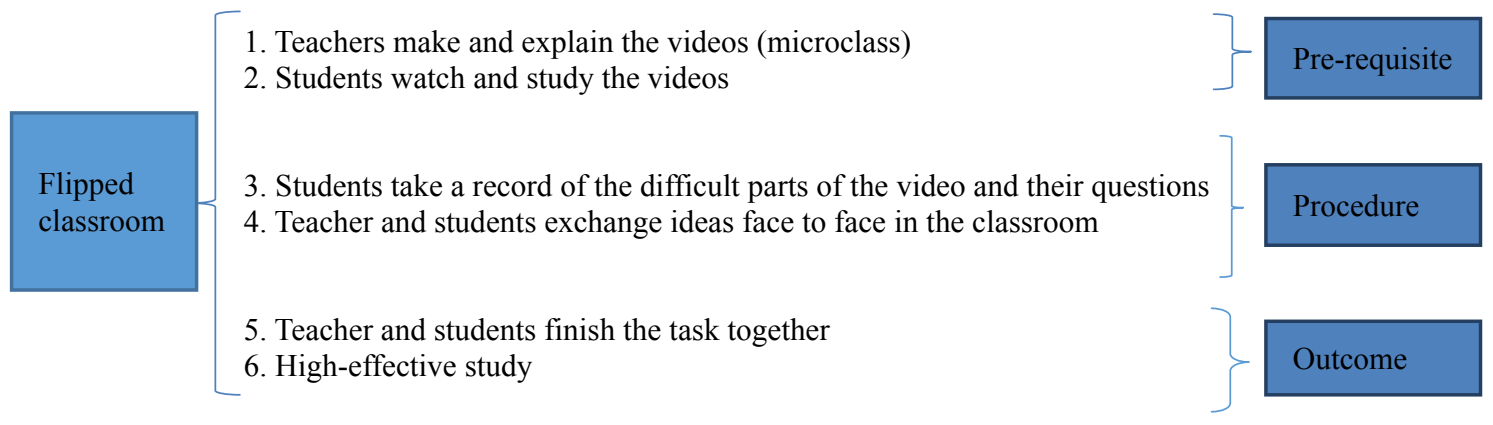

Figure 2. The basic procedure of flipped classroom.

Second, the teaching video of flipped classroom should be better controlled within 10 minutes, which is how long the students could focus on. The existing documentaries are too long for students to concentrate on, if cutting down some parts of it may result in fragmentation of the content system, and therefore cannot be the main source of teaching video. Finally, the subtitle arrangement may not meet the teaching requirements. In the 
language course, it is an important target to cultivate the student's listening and subtitles should not been always showed in the video. As we all know that language disorder affects the achievement of teaching objectives and the way to solve this problem is timely to add subtitles, therefore, the relatively viable way is to make the video own and ensure that the content and structure of the video and other details in line with the curriculum objectives. Problems occurred when the video and the teacher's teaching objectives failed to fully match. When we talk about "teaching video", most people will think of recording lessons with the camera. Although the teaching could be recorded in the process of an ongoing class, not every school could afford the high requirements of the hardware that is needed in the recording, teachers feel totally different when facing the machine and the real students, and some teachers are even too nervous to be language disordered. Under the living recording, reaction of teacher and students may also be unnatural or unreal. The original lively classroom may turn to gray due to the presence of the camera. That is why we need to find a humane way to improve the efficiency and quality of video. Then we find the simplest way is to use the cellphone. Put the mobile phone at the angle that all writings and presentation of teacher could be recorded and the teacher's plan will not be disturbed. By this way you can hear the teacher clearly and also see the calculus or demonstration process. In addition, there are some commonly used software devices that could provide us with videos with higher quality, such as recording software, video recording software, audio and video editing software, tablet and microphone and so on. The contents of power point teacher used in teaching and operating tracks could be recorded with the screen capture software, including Camtasia Studio, master screen, Power Video Maker and so on. How to make teaching video more attractive to the students and improve the quality of video production has become an important problem in building material basis for flipped classroom.

(1) Maintaining an appropriate length of the video.

Nowadays, most of the articles introducing flipped classroom are emphasizing on the shortness of the video to meet the students' need, which is also the product of our digital age. Teaching video production also follows the spirit of simplification. Practice has proved that most teaching video with clear teaching target should be controlled within 15 minutes and most of the Chinese teaching videos are controlled within 10 minutes. The liberal arts course usually contains a large amount of information and we can extend the video length appropriately to ensure the integrity of the knowledge structure. For the content of a large number of teaching units can be recorded individually, each video only involves one key point, for example, video focusing on the type of tea will only talk about tea types and tea ceremony will be produced by another independent video to explain. It is better to explain structures such as cause-effect, problem-solution-evaluation, and question-examples-conclusion respectively. Video that is too long or too complicated often becomes less effective

(2) Enhancing the power of sound.

Teachers often use power point explanation to assist teaching in the liberal arts course video, students thus might overlook about PPT style and ignore the learning context. Teachers are more passionate when they can communicate and have interaction with students directly, but when they face the computer, it is easy to appear pale and straightforward explanation and this voice will often cause students to burn out. Therefore, the process of making video should pay attention to enhancing the power of the sound.

(3) Paying attention to the use of humor.

Humorous elements in the teaching video make the learning process more relaxing. Humor is often associated with language and culture, which is used in stimulating students' learning interest at the same time 
also prompting the understanding with the language and culture that the humor relies on. But the use of humor should be within the control and too much jokes may turn humorous to be bored.

(4) Adding the necessary annotation.

Language course determines that all scripts cannot be synchronized with the video in teaching, which will make students depend on the transcription and thus influence their listening training. On the contrary, without transcription need students to reach a very high level in listening skill, if not, students may become less confident.

Therefore, suitable annotation for difficult phrases or expressions should be added in English teaching video. By this way, we can reduce the difficulty of hearing materials and also help students understand the context in-depth. It will be more convenient for students to search for related knowledge on the network according to the annotation offered in the video.

\section{The Organization of Teaching Activities During Class}

Watching the teaching video before class will help students to get better understanding about teaching material. Flipped classroom focuses on how to achieve a higher teaching goal by making full use of the class time.

In this study, the teaching material is taught to students by teaching video or guided case, so they can view the key point before class and use most of the class time to complete the relevant exercises and teaching activities.

(1) The network room is a prerequisite for college English courses based on the flipped classroom teaching model.

Considering the current situation, it is unrealistic to ask all students to take their own equipment (BYOD) to classroom, so some students need to watch video in school's computer room.

At the same time, English as a communication medium in the classroom for some students is not easy to understand, so that is how Internet could be their teacher and benefit them in mastering language vocabulary, providing relevant information, and broadening their horizon with its rich resources. For example, in Central South University of Forestry and Technology, students used to only use Internet to study in the computer room under the supervision and guidance from teachers. After reform, students now can arrange their own study in the dormitory by using their own computers anytime.

(2) Hierarchical teaching target provides the help of the smooth implementation of college English curriculum based on the flipped classroom.

Hierarchical teaching target makes a variety of classroom teaching activities with a clear purpose, which helps students be targeted and learn gradually from easy parts to hard parts. The hierarchical teaching objectives guided by Bloom's taxonomy of educational objectives not only guarantee the mastering of fundamental knowledge, but also motivate students to think much deeper about the subject. Students in the classroom can first solve the memory and understanding targets and then achieve the purpose of comprehensive use by group discussion, presentation, etc.

In this research, memory and understanding are tested by yes or no questions (to provide students with a certain information, asking students to determine whether this information is correct), the word meaning matching questions (to provide two lists for students to match, each item in the list A is paired with an entry in list B), multiple choice questions (to give the students a question and a few answers and let them to choose the best answer), and filling the blanks (to fill in the missing information with some notifications). 
Although the form of evaluation task has something in common, this test emphasizes on the emergence of new information during the test process. That is to say, students cannot get the right answer by just memorizing the answers.

As for the comprehensive use of high-level cognitive process, we need more comprehensive evaluation forms that need multi-level cognitive process including question and answer, writing, and oral reports.

(3) It is an effective way to accomplish the goal of curriculum teaching by combining individual learning and cooperative learning.

For most college students, their basic purpose of choosing a subject is to help their professional development, and then for interests. Elective courses are extra courses that beyond their regular learning tasks. So under the heavy learning pressure in everyday, they can hardly squeeze more off class time for elective class and that is why the effective use of time in class is particularly important.

In the elective classes, oriented by a clear teaching goal, students can solve some less difficult teaching objectives by themselves and achieve more complicated goals by group works. College English courses are in accordance with the "group heterogeneity, group homogeneity" principle of grouping on the basis of students' personal learning and understanding. Through the group to discuss the exchange, the debate between the group to contend, the group on behalf of the report, and students to learn the main body, teachers vary according to appropriate guidance. On the basis of individual learning and cooperative learning, it helps to not only cultivate the ability of students to learn independently, but also create a relaxed and harmonious learning atmosphere. To stimulate students' learning potential, everyone has to improve faster. Therefore, the classroom teaching activities in the individual learning and cooperative learning echo each other and are indispensable.

\section{Learning Effect Evaluation After Class}

Flipped classroom teaching achieves personalized learning effectively, but the realization of combining personalized evaluation and integrity evaluation system is quite difficult for teachers.

The college English course evaluates students by the combination of formative evaluation and final test in the following aspects:

(1) In-time evaluation. Experienced teachers can take a random test, such as simple questions in the class to judge whether students achieve their learning tasks or to what degree they digest the key concept in learning. This random test can easily find whether students understand the teaching material and then correct their misunderstanding in time, thus achieves personalized instruction according to their learning degree. There is no one definite regulation for evaluation. Usually, teachers get their learning degree of teaching target by giving different questions to different students. In the evaluation process, the most important part is the effective communication between teacher and students and the most important goal is to understand the teaching materials.

(2) Comprehensive presentation is an effective way to promote students' self-efficacy, which could affect or determine the choice of activity to a certain degree as well as how long we could persist or put effort on this activity. As for students, self-efficacy will affect their initiative to learn. There are many factors influencing their self-efficacy, such as the success in learning difficulty, stage achievement, or the help from their peers. Therefore, in order to promote their feeling of accomplishment, a variety way of achievement presentation should be provided for students to display in their own style. 
In the teaching practice, we find that no certain presentation is applied to all students and that is why, in addition to the common unit tests, oral reports with PPT, oral discussions, and small papers, students should be provided with a broader choice. We could encourage students to create new suitable display methods such as class debates, news interviews, performances and so on.

(3) Opening examination questions could ensure the accuracy of learning effectiveness evaluation. Fairness and confidentiality are the rules that must be followed during the examination. Applying high-tech method in the examination promotes the teaching reform but also provides a convenience for cheating the exam, which could be solved by adding opening test paper.

Because there is no standard answer, students must answer the question based on their own understanding of the content and analyze the problem themselves, which is hard for them to cheat during the test in a limited testing time to share different answers. Therefore, the opening examination is a relatively effective way of assessing the students.

\section{Conclusion}

As a new informationalized teaching method, flipped classroom together with microlessons plays a vital role in college English teaching. We should attach more importance to the three stages of pre-class, during class, and post-class in which perfect teaching effect can be achieved. Through every effort we can realize the wisdom campus sooner or later.

\section{References}

Ash, K. (2012). Educators view "flipped" model with a more critical eye. Education Week, 32(2), 6-7.

Bachman, L. F., \& Palmer, A. S. (1996). Language testing in practice. Oxford: OUP.

Bergmann, J., \& Sams, A. (2012). Flipping the classroom (pp. 42-43). San Bruno: Tech \& Learning.

Bernardin, H. J., \& Beatty, R. W. (1984). Performance appraisal: Assessing human behavior at work. Boston: Kent Publishers.

Berrett, D. (2012). How "flipping" the classroom can improve the traditional lecture. The Chronicle of Higher Education. Retrieved August 12, 2014 from http://chronicle.com/article/How-Flipping-the-Classroom/130857/

Fulton, K. (2012). Upside down and inside out: Flip your classroom to improve student learning. Learning and Leading With Technology, 39(8), 12-17.

Herreid, C. F., \& Schiller, N. A. (2013). Case studies and the flipped classroom. Journal of College Science Teaching, 42(5), $62-66$.

Mangan, K. (2013). Inside the flipped classroom. Chronicle of Higher Education, 60(5), 18-21.

Sams, A., \& Bergmann, J. (2013). Flip your students' learning. Educational Leadership, 7, 16-20.

ZHANG, F. (2016a). A study of the autonomous learning model of college English reading under the MOOC environment. Aussie-Sino Studies, 10, 47-48.

ZHANG, F. (2016b). Outline signal teaching method and college English reading teaching under the environment of MOOC. AMAHS International Conference, 12, 457-460.

ZHANG, F. (2016c). Research on teaching performance evaluation of college English based on MOOC. Journal of Residuals Science \& Technology, 13(8), 200.1-200.4.

ZHANG, F. (2017a). Quality-improving strategies of college English teaching based on microlesson and flipped classroom. English Language Teaching, 10(5), 243-249.

ZHANG, F. (2017b). Research on the college English teaching model of "Internet+Flipped classroom". International Journal of Intelligent Information and Management Science, 6(2), 57-59. 